\title{
Accounting for externalities in the measurement of productivity growth: the Malmquist cost productivity measure
}

\author{
E. Ball ${ }^{\mathrm{a}}$, R. Färe ${ }^{\mathrm{b}, \mathrm{c}, *}$, S. Grosskopf ${ }^{\mathrm{b}}$, O. Zaim ${ }^{\mathrm{d}}$ \\ ${ }^{\mathrm{a}}$ Economic Research Service, U.S.D.A., Washington, DC 20005-4788, USA \\ ${ }^{\mathrm{b}}$ Department of Economics, Oregon State University, Corvallis, OR 97331-3612, USA \\ c Department of Agricultural and Resource Economics, Oregon State University, \\ 319D Ballard Extension Hall, Corvallis, OR 97331-3612, USA \\ d Department of Economics, Bilkent University, 06533 Bilkent, Ankara, Turkey
}

Received 1 November 2003; received in revised form 1 March 2004; accepted 1 April 2004 Available online 4 August 2004

\begin{abstract}
This paper starts with the basic premise: that conventional measures of productivity growth-often used as a measure of corporate performance - which ignore external or social output, are biased. We then construct an alternative productivity growth measure using activity analysis which integrates the externality/social output into a generalized productivity measure reflecting social responsibility. This method is very general and could be applied to gauge corporate social responsibility. We provide an application to US agriculture to demonstrate the approach: we show that conventional measures of productivity are biased upward when production of negative externalities (or bad) outputs is increasing. Conversely, this same measure of productivity is biased downward when externalities in production are decreasing.

(C) 2004 Elsevier B.V.All rights reserved
\end{abstract}

JEL classification: D62; Q52

Keywords: Malmquist; Productivity; Externalities; Activity analysis; US agriculture

\footnotetext{
* Corresponding author. Tel.: +1 541737 8184; fax: +1 5417375917.

E-mail address: rolf.fare@orst.edu (R. Färe).
} 


\section{Introduction}

The purpose of this paper is to demonstrate how one of our most fundamental measures of performance — namely productivity growth—can be amended to account for nontraditional outputs, such as negative and positive externalities or other social outputs. The measure we propose, the Malmquist cost productivity measure (MCP) is a measure of total factor productivity that can readily integrate multiple outputs and is easily estimated. In order to make our proposed measure concrete, we illustrate its use with an application to the issue of performance in the agricultural sector when accounting for environmental degradation. Given the trend toward 'corporate' farming in the US, this provides a somewhat unusual, but we think relevant, example of measuring 'corporate' social performance, where our focus is on environmental responsibility.

More generally concerns about environmental degradation have prompted the adoption of measures that would internalize externalities in production. The measures taken, ranging from command and control policies such as regulation to more market oriented policies such as issuing tradable pollution permits, were aimed at preventing the use of the environment as a medium whereby undesirable (or bad) outputs could be freely disposed. This has required that models of production be extended to accommodate joint production of "goods" and "bads". Early contributors included Shephard (1970) and Shephard and Färe (1974).

Initial studies were more geared towards a comparative evaluation of environmental performance of decision making units (DMUs) within a static framework. Literature on production frontier construction is extended and modified to measure environmental performance in addition to capturing efficiency at the decision making unit (DMU) level. The two competing approaches, stochastic frontier estimation and data envelopment models, while determining the technology to be used as a basis for constructing different measures of DMU performance, they shared equal responsibility in providing means of measuring environmental performance. As a result, empirical applications on the measurement of environmental performance have flourished from both strands. For example while Reinhard et al. (1996) used a stochastic production frontier approach to construct environmental efficiency indexes at the farm level, Ball et al. (1994) and Tyteca (1997) adopted the data envelopment analysis to measure the environmental performance. Yet Reinhard et al. (1997) used both approaches on the same data set to "analyze the strengths and weaknesses of the two methods in computing the comprehensive environmental efficiency scores". Comparative studies such as Reinhard et al. (1997)'s confirmed the theoretically expected results. Since stochastic production frontiers contain a random error, which attribute some of the deviations from the frontier to uncontrollable chance events (and/or measurement errors), they have generated higher environmental efficiency scores than those measured by DEA, which is a deterministic technique that attributes all the deviations from the best practice to inefficiency. Nevertheless, these studies also showed that although the magnitude of environmental efficiency scores are different, both approaches generate very similar results in ranking DMU's with respect to environmental performance and that the difference in efficiency scores obtained from alternative approaches is a matter of scaling.

Stochastic production frontier models and DEA models also differed in their construction of the best practice technology. While DEA models satisfy monotonicity and curvature restrictions by construction without imposing a parametric structure on the technology, these 
restrictions can not be imposed in stochastic production frontier models when flexible functional forms are specified. Although the ability to test for the satisfaction of the theoretical restrictions considered to be a strength of SPF models, tests of monotonicity restrictions often time revealed that substantial number of observations violated this restriction. This further complicates the measurement issues in environmental performance by introducing specification errors. Hence, many studies that focused on measuring the cost of reduced disposability and the environmental performance of producers (see, for example, Färe et al., 1986, 1989a, 1989b, 1996; Tyteca, 1996, 1997; Zaim and Taskin, 2000; Ball et al., 2002a, 2002b, 2002c) stayed within DEA framework.

More recently, a large number of studies have been devoted to measuring the effects of environmental regulation on productivity growth. The results of these studies almost unanimously suggested that regulations retard productivity growth (see for example see for example Denison, 1979; Havemann and Christainsen, 1981; Gray, 1987; Robinson, 1995). Such a conclusion was inevitable since these studies have only concentrated on cost increasing aspects of regulatory policies without giving any credit to regulatory outcome-reduced bads and hence reduced marginal damage. As Ball et al. (2002a, 2002b, 2002c) point out, measures of productivity growth that ignore joint production of good and bad outputs and the restrictions on disposability of bad outputs will overstate the "social benefits" of production. They call for a revised measure of productivity growth that captures the cost associated with environmental externalities. This issue has been addressed within a "production" framework with the development of the Malmquist-Luenberger productivity index (see Chung et al., 1997; Ball et al., 2001; Hailu and Veeman, 2001).

The objective of the present study is to derive an alternative measure of productivity growth within a "cost" framework, which we term the Malmquist cost productivity (MCP) index, which extends Diewert's (1992) cost function technique by allowing for bads. We believe that the MCP measure represents an attractive alternative to the Malmquist-Luenberger index of productivity for several reasons. First, since it is augmented with price information on inputs as well as information on quantities of inputs and outputs it contains almost the same information as a traditional Tornqvist-type productivity indicator. Second, since the cost structure of an industry is a fundamental determinant of cost-effective production decisions, a cost framework as used in MCP is a desirable foundation for representing production patterns and analyzing the productive contributions of both good and bad outputs and inputs to production. Finally, the underlying activity analysis framework produces technically more feasible linear programming problems, which reduce the number of infeasible solutions as compared to linear programming problems that are required for the computation of Malmquist-Luenberger index of productivity.

In constructing our MCP index, we rely on activity analysis which conveniently allows us to model joint production of good and bad outputs, thereby putting due emphasis on the characteristics of production with negative externalities. The basic building blocks of our approach are as follows. First, we explicitly account for joint production of good and bad outputs. Second, our representation of technology reflects restrictions on the disposability of bad outputs. This implies that the reduction of bad outputs is possible either by reducing the production of good outputs given a fixed level of inputs (where some inputs must be diverted from the production of goods to the reduction of bads) or by increasing input use (again to reduce bad outputs) while maintaining the same level of production of good 
outputs. Notice that in either case the reduction of bad outputs is achieved by increased cost to the producer, since the environment ceases to be a free factor of production with a positive marginal benefit to the producer. ${ }^{1}$ Finally, we assume that bad outputs are always produced when good outputs are produced, thereby ruling out production of good outputs with no environmentally detrimental impacts. In addition we do not have to introduce separability between good and bad outputs in our framework, in contrast to Fernandez et al. (2002).

The paper unfolds as follows: Section 2 introduces the MCP index and its decomposition into efficiency change and technical change components. In Section 3, we apply the proposed index to a state-by-year panel recently made available by the US Department of Agriculture's (USDA) Economic Research Service. Section 4 concludes.

\section{The theoretical underpinnings}

In this section, we introduce the cost-based Malmquist productivity index. The cost functions on which our index is based are computed using an "environmental" activity analysis model. By "environmental" we mean that the model incorporates both good and bad outputs and that these outputs are weakly disposable and null-joint. A mathematical representation is provided below. In words, weak disposability implies that feasible outputs (good or bad) can be proportionally reduced. Null-jointness implies that to produce good outputs, some bad outputs must also be produced. There cannot be fire without smoke.

We begin with some notation. Let us denote desirable (or good) outputs by $y=$ $\left(y_{1}, \ldots, y_{M}\right) \in R_{+}^{M}$ and undesirable (or bad) outputs by $b=\left(b_{1}, \ldots, b_{I}\right) \in R_{+}^{I}$. The vector of outputs $(y, b)=\left(y_{1}, \ldots, y_{M}, b_{1}, \ldots, b_{I}\right)$ is produced from inputs $x=\left(x_{1}, \ldots, x_{N}\right) \in R_{+}^{N}$ using technology

$$
T=\{(x, y, b): x \text { can produce }(y, b)\} .
$$

Next we formulate the technology as an activity analysis model. We assume that there are $K$ observations on inputs and outputs, where $k$ indexes firms (or states):

$$
\left\{\left(x^{k}, y^{k}, b^{k}\right): k=1, \ldots, K\right\} .
$$

Following Shephard (1970, p. 283) we assume that

$$
\begin{array}{ll}
\text { (i) } & \sum_{k=1}^{K} x_{k n}>0, \quad n=1, \ldots, N . \\
\text { (ii) } & \sum_{n=1}^{N} x_{k n}>0, \quad k=1, \ldots, K . \\
\text { (iii) } & \sum_{k=1}^{K} y_{k m}+\sum_{k=1}^{K} b_{k i}>0, \quad m=1, \ldots, M, i=1, \ldots, I . \\
\text { (iv) } \sum_{m=1}^{M} y_{k m}+\sum_{i=1}^{I} b_{k i}>0, \quad k=1, \ldots, K .
\end{array}
$$

\footnotetext{
1 This property, which is referred to as weak disposability in the non-parametric production frontier literature, is also adopted by studies that utilize parametric approaches. In parametric models this is a derivative property which implies that the partial derivative of cost with respect to a bad output is negative (see Ball et al., 2002a, 2002b, 2002c).
} 
Condition (i) says that each input must be used in at least one activity and (ii) says that each activity must use at least one input. Conditions (iii) and (iv) for outputs mimic conditions (i) and (ii) for inputs.

In addition to conditions (i)-(iv) we assume that outputs (good or bad) are weakly disposable. In terms of $T$ this means that (Shephard, 1970)

$$
(x, y, b) \in T \text { and } 0 \leq \theta \leq 1 \text { imply }(x, \theta y, \theta b) \in T .
$$

In words, a proportional contraction of feasible outputs is feasible. This models the idea that it is costly in terms of good outputs to decrease production of bads. We will model this by use of equalities in our activity analysis setting.

The bad outputs are assumed to be byproducts of production of good outputs which is modelled by null-jointness. Formally (see Shephard and Färe, 1974)

$$
(x, y, b) \in T \text { and } b=0 \text { imply } y=0 .
$$

In words, if no bads are produced then it is not feasible to produce good outputs. Thus we interpret the bads as byproducts or joint products of good productionand therefore treat them as outputs. This condition is imposed by assuming that

$$
\begin{aligned}
& \text { (v) } \sum_{k=1}^{K} b_{k i}>0, \quad i=1, \ldots, I . \\
& \text { (vi) } \sum_{i=1}^{I} b_{k i}>0, \quad k=1, \ldots, K .
\end{aligned}
$$

The first set of inequalities says that each bad output is produced by at least one activity, and (vi) tell us that each activity produces at least one bad output.

If, in addition, we assume that good outputs are freely disposable as represented by expression (7) below

$$
(x, y, b) \in T \quad \text { and } \quad y^{\prime} \leq y \text { imply }\left(x, y^{\prime}, b\right) \in T
$$

then our activity analysis model of technology is

$$
\begin{aligned}
& T=\left\{(x, y, b): \sum_{k=1}^{K} z_{k} x_{k n} \leq x_{n}, \quad n=1, \ldots, N,\right. \\
& \sum_{k=1}^{K} z_{k} y_{k m} \geq y_{m}, \quad m=1, \ldots, M, \\
& \left.\sum_{k=1}^{K} z_{k} b_{k i}=b_{i}, \quad i=1, \ldots, I, \quad z_{k} \geq 0, \quad k=1, \ldots, K\right\},
\end{aligned}
$$

where $z_{k}, k=1, \ldots, K$, are intensity variables.

Given input prices $w=\left(w_{1}, \ldots, w_{N}\right) \in R_{+}^{N}$, then following Shephard (1970), we may compute minimum cost by solving the linear programming problem

$$
C(y, b, w)=\min \{w x:(x, y, b) \in T\} .
$$


Now suppose that for each observation $k$, we have observations for each time period $t, t=$ $1, \ldots, T$. Then we can compute the cost functions that make up our Malmquist productivity index. Suppressing the subscript $k$, these cost functions are

$$
\begin{aligned}
& c^{t}\left(y^{t+1}, b^{t+1}, w^{t+1}\right) \\
& c^{t}\left(y^{t}, b^{t}, w^{t}\right) \\
& c^{t+1}\left(y^{t+1}, b^{t+1}, w^{t+1}\right) \\
& c^{t+1}\left(y^{t}, b^{t}, w^{t}\right) .
\end{aligned}
$$

If we denote the observed cost by

$$
c^{t}=\sum_{n=1}^{N} w_{n}^{t} x_{n}^{t} \quad \text { and } \quad c^{t+1}=\sum_{n=1}^{N} w_{n}^{t+1} x_{n}^{t+1},
$$

the Malmquist cost productivity (MCP) index is given by

$$
\operatorname{MCP}_{t}^{t+1}=\left[\frac{c^{t}\left(y^{t+1}, b^{t+1}, w^{t+1}\right) \cdot c^{t+1}\left(y^{t+1}, b^{t+1}, w^{t+1}\right)}{c^{t}\left(y^{t}, b^{t}, w^{t}\right) \cdot c^{t+1}\left(y^{t}, b^{t}, w^{t}\right)}\right]^{1 / 2} \frac{c^{t}}{c^{t+1}}
$$

This index may be derived either from the usual Malmquist (input-based) productivity index assuming allocative efficiency or from the cost-indirect index by assuming constant returns to scale (see Färe et al., 1994).

Like other Malmquist productivity indexes, this index can be decomposed into an efficiency change and a technical change component. The efficiency change component is

$$
\operatorname{EFFCH}_{t}^{t+1}=\frac{C^{t+1}\left(y^{t+1}, b^{t+1}, w^{t+1}\right) / c^{t+1}}{C^{t}\left(y^{t}, b^{t}, w^{t}\right) / c^{t}},
$$

and the technical change component is

$$
\mathrm{TECH}_{t}^{t+1}=\left[\frac{C^{t}\left(y^{t+1}, b^{t+1}, w^{t+1}\right)}{C^{t+1}\left(y^{t+1}, b^{t+1}, w^{t+1}\right)} \frac{C^{t}\left(y^{t}, b^{t}, w^{t}\right)}{C^{t+1}\left(y^{t}, b^{t}, w^{t}\right)}\right]^{1 / 2} .
$$

The product of the two component measures equals the productivity index

$$
\mathrm{MCP}_{t}^{t+1}=\mathrm{EFFCH}_{t}^{t+1} \cdot \mathrm{TECH}_{t}^{t+1} .
$$

Before we illustrate the MCP index and its decomposition we note that the efficiency change component (13) consists of the ratio of two Farrell (1957) measures of cost efficiencies, namely for time $t+1$ :

(minimum cost in $t+1) /($ observed cost in $t+1)$, the numerator of (13)

And for time $t$

(minimum cost in $t) /($ observed cost in $t)$, the denominator of (13).

In order to illustrate our decomposition, let CT $(t)$ represent the solution to (9) for period $t$. If we suppress the $b$ and $w$ arguments for the moment as well, we can sketch the decomposition 
in terms of good output y and $\operatorname{cost} c$. See the following figure for an illustration for the two periods $t$ and $t+1$.

The two period frontiers are constructed from the cost minimizers in each period. Observed cost $c(t)$ is associated with observed output in period t namely $y(t)$. Similarly we have observed cost and output in period $t+1, c(t+1), y(t+1)$.

In our figure the cost components from expression (10) correspond to the following:

- Minimum cost in period $t$ using $t+1$ data $=f$.

- Minimum cost in period $t$ using $t$ data $=b$.

- Minimum cost in period $t+1$ using $t+1$ data $=e$.

- Minimum cost in period $t+1 \mathrm{using} t$ data $=c$.

Thus in our figure, the efficiency change comonent of MCP is:

$$
\frac{\mathrm{Oe} / \mathrm{Od}}{\mathrm{Ob} / \mathrm{Oa}}
$$

and the technical change component is

$$
\left[\left(\frac{\mathrm{Of}}{\mathrm{Oe}}\right)\left(\frac{\mathrm{Ob}}{\mathrm{Oc}}\right)\right]^{1 / 2}
$$

and hence the overall MCP index equals

$$
\left[\left(\frac{\mathrm{Of}}{\mathrm{Ob}}\right)\left(\frac{\mathrm{Oe}}{\mathrm{Oc}}\right)\right]^{1 / 2}\left(\frac{\mathrm{Oa}}{\mathrm{Od}}\right) .
$$

In this paper, we have chosen to estimate the CMP using an Activity Analysis Model. Other choices would be to parameterize the cost function, say with a translog function, and esimtate its parameters using linear programming (Aigner and Chu, 1968) or as a stochastic frontier.

Our approach has the advantage that no parametric form is required. However, measurement error may affect the results. Our choice is conditioned on our faith in our data. Another issue which we have not addressed here but would be a possible extension, is to include confidence intervals to provide evidence on statistical significance of our estimates. See recent work by Simar and Wilson (e.g., 2000) for bootstrapping approaches to construct confidence intervals and pursue statistical inference in a DEA framework.

We note that the Malmquist index (15) contains mixed period cost functions $C^{t}\left(y^{t+1}, b^{t+1}, w^{t+1}\right)$ and $C^{t+1}\left(y^{t}, b^{t}, w^{t}\right)$. For some observations, the corresponding input sets may be empty, implying that the value of the cost function is infinity. Under such conditions, the Malmquist index is undefined. These are identified as "infeasible solutions" in the empirical section of this paper. A possible extension of the work here which might reduce problems of infeasibility is to introduce a window approach. The general idea is to include past periods in order to increase the number of observations in the reference technology. 


\section{Measurement of productivity growth in US agriculture}

Our proposed index is used to measure productivity growth in the US farm sector. Our data consist of a state-by-year panel containing price and quantity indexes for two "good" outputs (crops and livestock) and four inputs (capital, land, labor, and materials). ${ }^{2}$

A unique feature of our data series is that it also contains a number of "bad" outputs, which is crucial to our analysis of productivity growth. The bad outputs are indicators of risk to human health from chronic exposure to agricultural pesticides. We construct indicators of risk from exposure to pesticide runoff and to pesticides leaching into groundwater.

Our assessment of risk is based on the extent to which the concentration of a specific pesticide exceeds a water quality threshold. For each of some 200 pesticides applied to 12 crops, we estimate the annual concentration at the bottom of the root zone and at the edge of the field for 4700 representative soils. These concentrations are compared to water quality thresholds that represent "safe" levels for chronic exposure. When the concentration of a specific pesticide exceeds the threshold, an indicator of risk is constructed using the concentration-threshold ratio. More specifically, we estimate the number of "threshold exceedence units" for each pesticide and then sum across all pesticides used. ${ }^{3}$

In our empirical analysis, we include only 46 of 48 states. This is because of our requirement that the technology satisfy null-jointness. For two states Nevada and Rhode Island, we observe zero production of bad outputs for some years. This does not imply that there was zero environmental risk. Rather, the pesticide concentration in some years did not exceed the water quality threshold.

We begin by computing the MCP index including only good outputs. This provides a benchmark which can be used to assess the bias associated with ignoring bad outputs. We report the average annual rates of change in the MCP index and its decomposition into technical change and change in efficiency in Table 1 for each of the 46 states in our sample. Recall that values greater than unity indicate an improvement in productivity performance, while values less than unity indicate deterioration. Remarkably, every state exhibits a positive and generally substantial average annual rate of productivity growth. Moreover, our results suggest that technical change dominates efficiency change as a source of productivity growth.

Before reporting productivity growth rates that account for the detrimental effects on water quality, we examine the trends in production of the bad outputs. Fig. 1 plots the time paths of both pesticide leaching and runoff for the period 1960-1996 for the aggregate farm sector. We observe an upward trend in both pesticide leaching and runoff between 1960 and 1974. The two series trended downward between 1976 and 1984. After 1984, pesticide leaching resumed its upward trend, while pesticide runoff continued to decline. ${ }^{4}$

\footnotetext{
${ }^{2}$ A description of the data can be found in Ball et al. (2002a).

3 A detailed discussion of the construction of these series is provided in Kellogg et al. (2002).

${ }^{4}$ We attribute the observed reduction in risk from exposure to pesticides to passage of the Federal Environmental Pest Control Act (FEPCA) of 1972, which significantly increased authority to regulate pesticides. The FEPCA allowed registration of a pesticide only if it did not cause unreasonable adverse effects to human health or the environment. It also required an examination of the safety of all previously registered pesticides using new health and environmental criteria. Pesticides with risks that exceeded those criteria were subject to cancellation.
} 
Table 1

Productivity growth in US agriculture, 1960-1996

\begin{tabular}{|c|c|c|c|}
\hline STATE & $\mathrm{MCP}$ & EFFCH & TECH \\
\hline $\mathrm{AL}$ & 1.0267 & 1.0034 & 1.0232 \\
\hline $\mathrm{AR}$ & 1.0360 & 1.0096 & 1.0262 \\
\hline $\mathrm{AZ}$ & 1.0071 & 0.9813 & 1.0263 \\
\hline $\mathrm{CA}$ & 1.0241 & 0.9980 & 1.0262 \\
\hline $\mathrm{CO}$ & 1.0219 & 0.9951 & 1.0269 \\
\hline CT & 1.0346 & 1.0102 & 1.0241 \\
\hline DE & 1.0336 & 1.0078 & 1.0256 \\
\hline FL & 1.0287 & 1.0000 & 1.0287 \\
\hline GA & 1.0382 & 1.0113 & 1.0266 \\
\hline IA & 1.0210 & 0.9964 & 1.0247 \\
\hline ID & 1.0321 & 1.0026 & 1.0294 \\
\hline IL & 1.0247 & 0.9952 & 1.0297 \\
\hline IN & 1.0265 & 0.9974 & 1.0292 \\
\hline KS & 1.0213 & 0.9945 & 1.0269 \\
\hline $\mathrm{KY}$ & 1.0269 & 0.9991 & 1.0278 \\
\hline LA & 1.0368 & 1.0084 & 1.0282 \\
\hline MA & 1.0291 & 1.0048 & 1.0242 \\
\hline MD & 1.0258 & 1.0025 & 1.0233 \\
\hline $\mathrm{ME}$ & 1.0240 & 0.9997 & 1.0242 \\
\hline MI & 1.0312 & 1.0037 & 1.0274 \\
\hline $\mathrm{MN}$ & 1.0192 & 0.9952 & 1.0241 \\
\hline MO & 1.0184 & 0.9944 & 1.0242 \\
\hline MS & 1.0375 & 1.0081 & 1.0291 \\
\hline MT & 1.0150 & 0.9866 & 1.0289 \\
\hline $\mathrm{NC}$ & 1.0393 & 1.0108 & 1.0282 \\
\hline ND & 1.0295 & 1.0007 & 1.0288 \\
\hline $\mathrm{NE}$ & 1.0265 & 0.9983 & 1.0282 \\
\hline $\mathrm{NH}$ & 1.0261 & 1.0004 & 1.0257 \\
\hline $\mathrm{NJ}$ & 1.0260 & 1.0000 & 1.0260 \\
\hline NM & 1.0257 & 0.9998 & 1.0258 \\
\hline NY & 1.0171 & 0.9932 & 1.0241 \\
\hline $\mathrm{OH}$ & 1.0233 & 0.9946 & 1.0288 \\
\hline $\mathrm{OK}$ & 1.0155 & 0.9896 & 1.0261 \\
\hline OR & 1.0243 & 0.9961 & 1.0283 \\
\hline PA & 1.0263 & 1.0010 & 1.0253 \\
\hline $\mathrm{SC}$ & 1.0374 & 1.0082 & 1.0289 \\
\hline SD & 1.0209 & 0.9980 & 1.0230 \\
\hline TN & 1.0199 & 0.9956 & 1.0244 \\
\hline TX & 1.0175 & 0.9930 & 1.0246 \\
\hline UT & 1.0151 & 0.9896 & 1.0258 \\
\hline VA & 1.0255 & 1.0005 & 1.0249 \\
\hline VT & 1.0282 & 1.0030 & 1.0251 \\
\hline WA & 1.0334 & 1.0017 & 1.0316 \\
\hline WI & 1.0109 & 0.9892 & 1.0219 \\
\hline WV & 1.0151 & 0.9919 & 1.0234 \\
\hline WY & 1.0103 & 0.9828 & 1.0280 \\
\hline
\end{tabular}




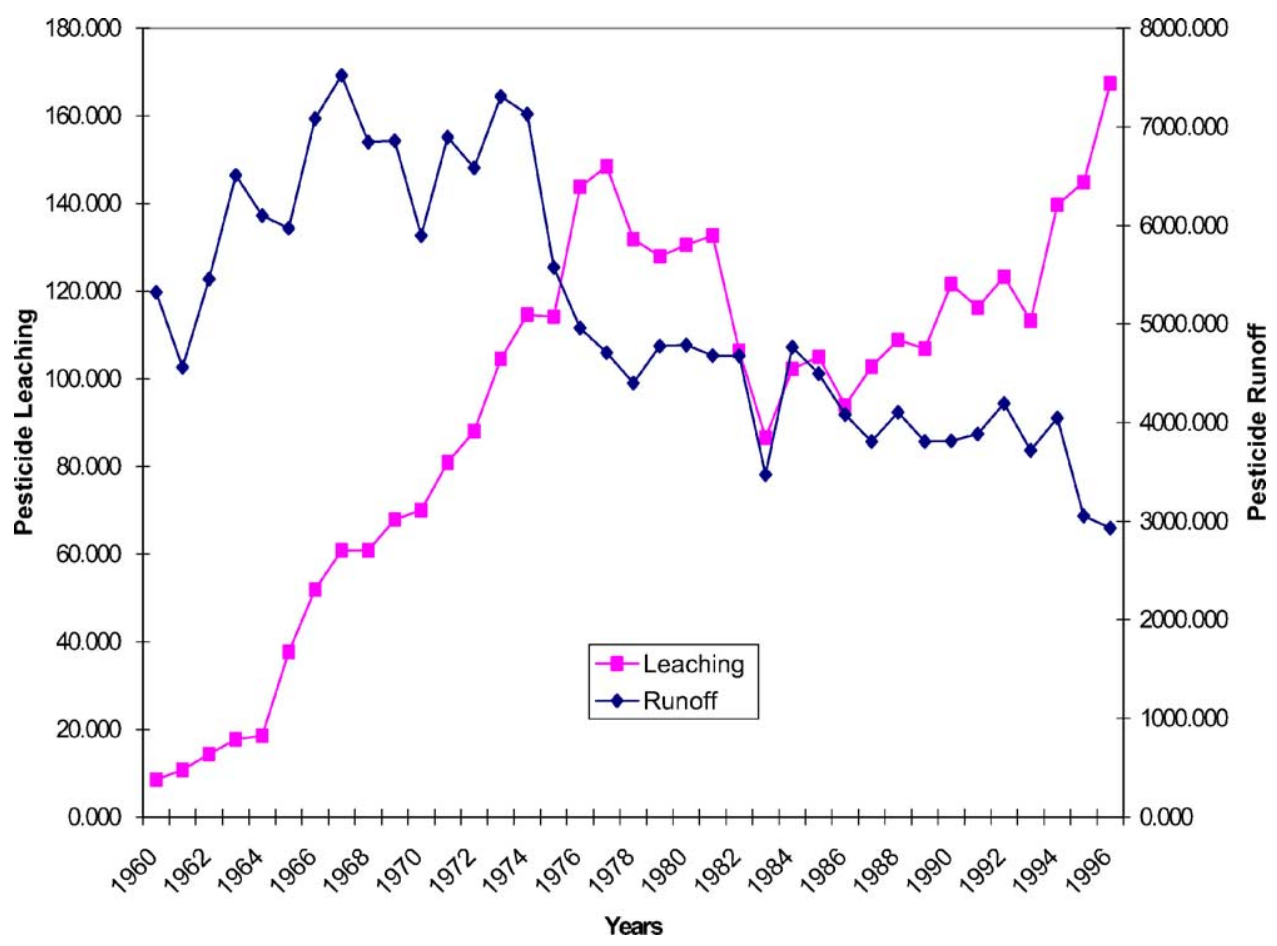

Fig. 1. Environmental indicators for US agriculture, 1960-1996 (in million TEUs).

Average annual rates of change in pesticide leaching and runoff for each of the 46 states are reported in Table 2 for the complete 1960-1996 period and for two subperiods-1960-1974 and 1974-1996. Our choice of sub-periods delineates the era of increased regulatory scrutiny of pesticides. ${ }^{5}$ During the $1960-1974$ period, all 46 states in our sample exhibited increases in pesticide leaching. Although the growth rates slowed dramatically during the 1974-1996 period, few states actually reduced pesticide leaching. In fact, the level of pesticide leaching in 1996 exceeded that in 1960 in every state. As for pesticide runoff, the positive growth rates observed during the 1960-1974 period were largely reversed during the subsequent time period. Thirty-six of 46 states reduced pesticide runoff between 1974 and 1996. Twenty-five states achieved reductions from 1960 levels.

The risk from pesticide leaching and runoff varied markedly over space as well as over time. The spatial distributions for the two indicators are displayed in Figs. 2 and 3. We see that the risk from pesticide runoff is greatest in the Upper Mississippi, Ohio, and Great Lakes Water Resource Regions. The risk from pesticide leaching is high in some of these same areas, but is also a concern in the South Atlantic and Gulf regions.

This brings us to the main theme of this paper, the measurement of productivity when there are externalities in production. Table 3 provides estimates of productivity growth

\footnotetext{
${ }^{5}$ See footnote 2 above.
} 
Table 2

Growth rates of undesirable outputs, 1960-1996

\begin{tabular}{|c|c|c|c|c|c|c|}
\hline \multirow[t]{2}{*}{ State } & \multicolumn{3}{|c|}{ Average annual growth rates (leaching) } & \multicolumn{3}{|c|}{ Average annual growth rates (runoff) } \\
\hline & 1960-1974 & 1974-1996 & 1960-1996 & 1960-1974 & 1974-1996 & 1960-1996 \\
\hline AL & 0.1893 & -0.0230 & 0.0596 & -0.0491 & -0.0257 & -0.0348 \\
\hline $\mathrm{AR}$ & 0.2477 & 0.0536 & 0.1291 & 0.1083 & 0.0008 & 0.0426 \\
\hline $\mathrm{AZ}$ & 0.3689 & 0.1396 & 0.2299 & 0.0754 & -0.0863 & -0.0234 \\
\hline $\mathrm{CA}$ & 0.0248 & 0.0285 & 0.0270 & 0.0166 & 0.0326 & 0.0264 \\
\hline $\mathrm{CO}$ & 0.0650 & 0.0193 & 0.0371 & 0.1729 & -0.0873 & 0.0139 \\
\hline $\mathrm{CT}$ & 0.3437 & -0.0231 & 0.1196 & 0.1063 & -0.0322 & 0.0216 \\
\hline $\mathrm{DE}$ & 0.2161 & -0.0097 & 0.0781 & -0.1025 & -0.0160 & -0.0496 \\
\hline FL & 0.2336 & -0.0165 & 0.0807 & -0.1730 & -0.0245 & -0.0822 \\
\hline GA & 0.1669 & 0.0342 & 0.0858 & -0.1500 & -0.0106 & -0.0648 \\
\hline IA & 0.3730 & 0.0002 & 0.1452 & 0.0366 & -0.0434 & -0.0123 \\
\hline ID & 0.1061 & -0.0122 & 0.0338 & 0.0843 & -0.0765 & -0.0140 \\
\hline IL & 0.2020 & 0.0167 & 0.0887 & -0.0211 & -0.0359 & -0.0301 \\
\hline IN & 0.3292 & 0.0052 & 0.1312 & 0.0560 & -0.0649 & -0.0179 \\
\hline $\mathrm{KS}$ & 0.2511 & 0.0148 & 0.1067 & 0.0582 & -0.0383 & -0.0008 \\
\hline KY & 0.2063 & 0.0227 & 0.0941 & -0.0151 & 0.0092 & -0.0002 \\
\hline LA & 0.2269 & 0.0689 & 0.1303 & 0.0798 & 0.0272 & 0.0476 \\
\hline MA & 0.3406 & -0.0270 & 0.1160 & 0.1358 & -0.0056 & 0.0494 \\
\hline MD & 0.2476 & 0.0010 & 0.0969 & -0.1028 & 0.0208 & -0.0273 \\
\hline $\mathrm{ME}$ & 0.4849 & -0.2771 & 0.2299 & 0.1005 & -0.0466 & 0.0106 \\
\hline MI & 0.2518 & -0.0182 & 0.0868 & 0.0747 & -0.0099 & 0.0230 \\
\hline $\mathrm{MN}$ & 0.3456 & -0.0310 & 0.1155 & 0.1013 & -0.0263 & 0.0233 \\
\hline MO & 0.2320 & 0.0129 & 0.0981 & 0.0103 & -0.1104 & -0.0634 \\
\hline MS & 0.2554 & 0.0250 & 0.1146 & 0.0664 & -0.0068 & 0.0217 \\
\hline MT & 0.0288 & 0.0186 & 0.0225 & 0.1487 & -0.1034 & -0.0053 \\
\hline $\mathrm{NC}$ & 0.3073 & 0.0436 & 0.1462 & -0.0931 & -0.0725 & -0.0805 \\
\hline ND & 0.3569 & -0.1326 & 0.0578 & 0.0411 & -0.0378 & -0.0071 \\
\hline NE & 0.2877 & 0.0160 & 0.1217 & 0.0542 & -0.0229 & 0.0071 \\
\hline $\mathrm{NH}$ & 0.3654 & -0.1520 & 0.0610 & 0.2777 & -0.0027 & 0.1127 \\
\hline $\mathrm{NJ}$ & 0.2883 & -0.0267 & 0.0958 & 0.0629 & 0.0352 & 0.0460 \\
\hline NM & 0.2566 & 0.0013 & 0.1006 & 0.1147 & -0.0923 & -0.0118 \\
\hline NY & 0.4502 & -0.0129 & 0.1672 & 0.3276 & -0.0060 & 0.1237 \\
\hline $\mathrm{OH}$ & 0.3560 & -0.0341 & 0.1176 & 0.0073 & -0.0687 & -0.0392 \\
\hline $\mathrm{OK}$ & 0.1725 & 0.0637 & 0.1060 & 0.0569 & -0.0696 & -0.0204 \\
\hline OR & 0.1375 & 0.0769 & 0.1004 & -0.0091 & 0.0117 & 0.0036 \\
\hline PA & 0.3362 & -0.0187 & 0.1193 & 0.1168 & 0.0225 & 0.0592 \\
\hline $\mathrm{SC}$ & 0.2528 & 0.0134 & 0.1065 & -0.1082 & -0.0460 & -0.0702 \\
\hline SD & 0.1664 & -0.0567 & 0.0301 & 0.0764 & -0.0358 & 0.0078 \\
\hline TN & 0.1745 & 0.0076 & 0.0725 & 0.0114 & -0.0123 & -0.0031 \\
\hline $\mathrm{TX}$ & 0.2214 & -0.0010 & 0.0855 & 0.0719 & -0.0467 & -0.0005 \\
\hline UT & 0.0990 & 0.0589 & 0.0754 & 0.1426 & -0.0571 & 0.0206 \\
\hline VA & 0.3436 & 0.0000 & 0.1336 & -0.0948 & -0.0468 & -0.0655 \\
\hline VT & 0.3048 & 0.0195 & 0.1305 & 0.2811 & 0.0135 & 0.1176 \\
\hline WA & 0.1147 & 0.0924 & 0.1010 & 0.0404 & 0.0010 & 0.0163 \\
\hline WI & 0.3505 & -0.0302 & 0.1178 & 0.3231 & -0.0017 & 0.1246 \\
\hline WV & 0.1588 & -0.0345 & 0.0407 & -0.0718 & -0.0070 & -0.0322 \\
\hline WY & 0.1944 & 0.0758 & 0.1219 & 0.1380 & -0.1174 & -0.0181 \\
\hline
\end{tabular}




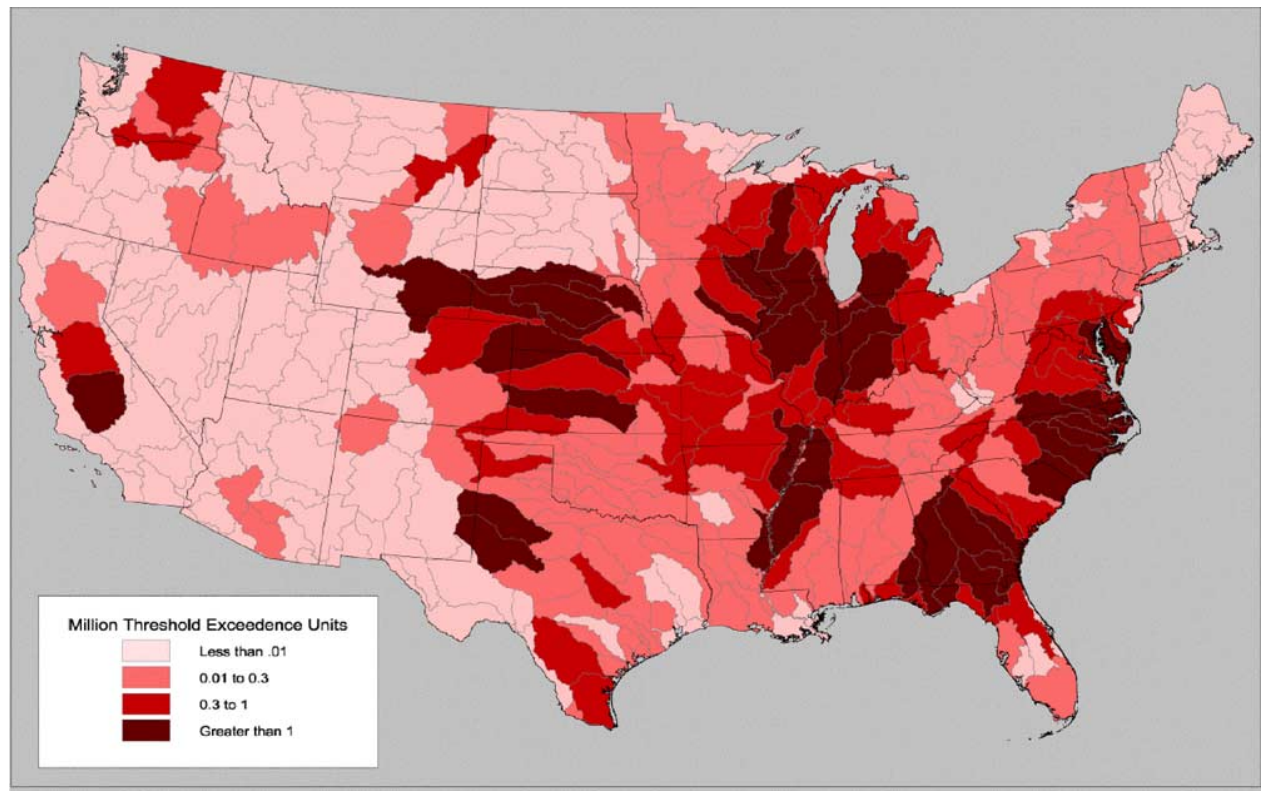

Fig. 2. Regional distribution of pesticide leaching, 1996 (in million TEUs).

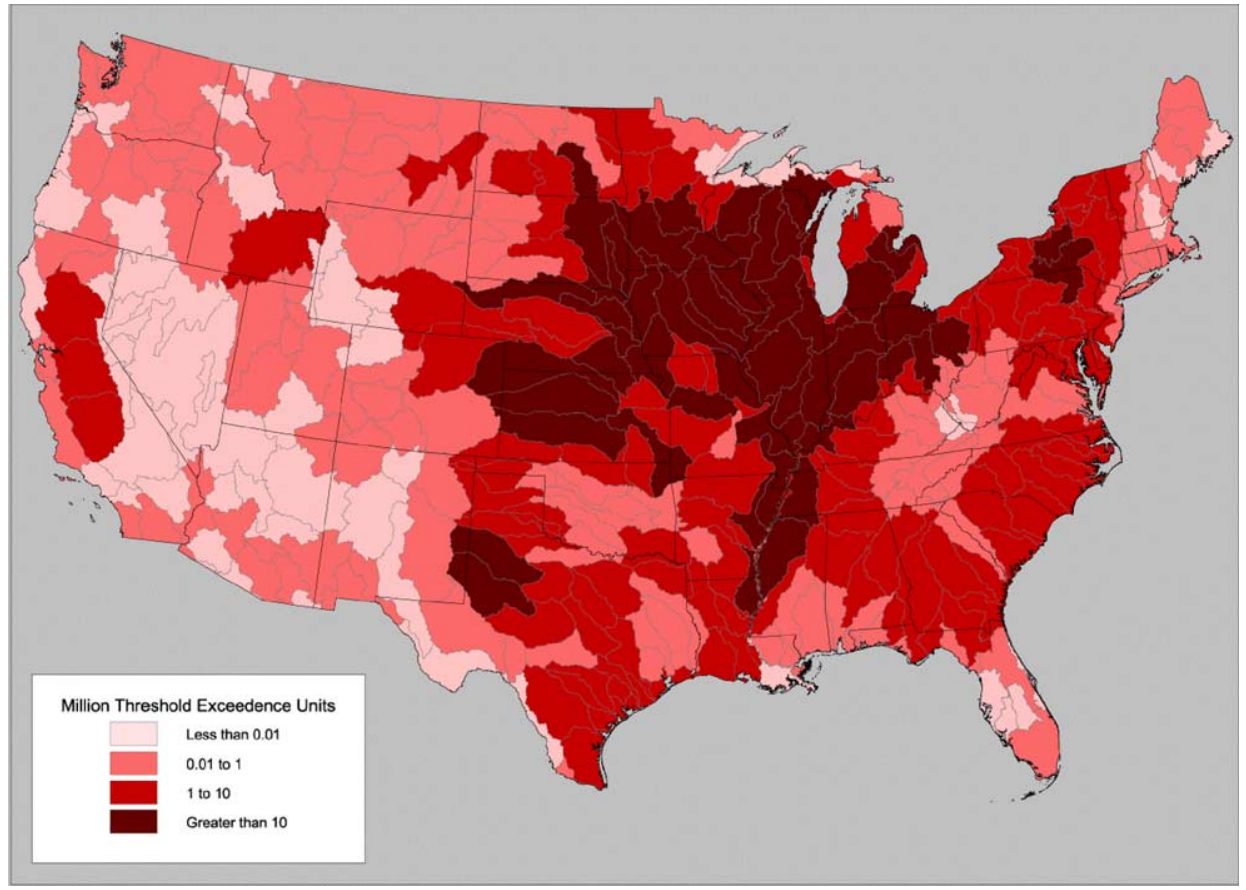

Fig. 3. Regional distribution of pesticide runoff, 1996 (in million TEUs). 
Table 3

Productivity growth including and excluding bads

\begin{tabular}{|c|c|c|c|c|c|c|c|}
\hline & \multicolumn{3}{|c|}{ MCP including bads } & \multirow{2}{*}{$\begin{array}{l}\text { Infeasible } \\
\text { solutions }\end{array}$} & \multicolumn{3}{|c|}{ MCP excluding bads } \\
\hline & 1960-1974 & 1974-1996 & 1960-1996 & & 1960-1974 & 1974-1996 & 1960-1996 \\
\hline $\mathrm{AL}$ & 1.2108 & 1.0220 & 1.0968 & & 1.0336 & 1.0219 & 1.0267 \\
\hline AR & 1.0419 & 1.0301 & 1.0350 & 24 & 1.0460 & 1.0289 & 1.0360 \\
\hline $\mathrm{AZ}$ & 0.9916 & 1.0728 & 1.0247 & & 1.0120 & 1.0036 & 1.0071 \\
\hline $\mathrm{CA}$ & 1.0171 & 1.0217 & 1.0212 & 18 & 1.0282 & 1.0212 & 1.0241 \\
\hline $\mathrm{CO}$ & 1.0110 & 1.0320 & 1.0232 & & 1.0229 & 1.0212 & 1.0219 \\
\hline CT & 1.0191 & 1.0526 & 1.0385 & & 1.0222 & 1.0435 & 1.0346 \\
\hline $\mathrm{DE}$ & 1.2514 & 1.0078 & 1.1324 & 10 & 1.0384 & 1.0301 & 1.0336 \\
\hline FL & 1.0460 & 1.0261 & 1.0390 & 16 & 1.0430 & 1.0186 & 1.0287 \\
\hline GA & 1.3166 & 1.0204 & 1.1493 & 6 & 1.0516 & 1.0287 & 1.0382 \\
\hline IA & 0.5595 & 0.9706 & 0.7716 & & 1.0132 & 1.0267 & 1.0210 \\
\hline ID & 1.0123 & 1.0358 & 1.0254 & 11 & 1.0330 & 1.0314 & 1.0321 \\
\hline IL & 0.9947 & 1.0166 & 1.0074 & & 1.0261 & 1.0238 & 1.0247 \\
\hline IN & 1.0277 & 1.0190 & 1.0226 & & 1.0244 & 1.0280 & 1.0265 \\
\hline $\mathrm{KS}$ & 1.0250 & 1.0242 & 1.0245 & & 1.0207 & 1.0218 & 1.0213 \\
\hline KY & 1.0193 & 1.0293 & 1.0252 & & 1.0226 & 1.0299 & 1.0269 \\
\hline LA & 1.0375 & 1.0279 & 1.0319 & & 1.0430 & 1.0324 & 1.0368 \\
\hline MA & 0.9982 & 1.0285 & 1.0168 & 2 & 1.0308 & 1.0278 & 1.0291 \\
\hline MD & 1.0901 & 1.0308 & 1.0551 & & 1.0304 & 1.0226 & 1.0258 \\
\hline $\mathrm{ME}$ & 0.9906 & 1.0128 & 1.0013 & 7 & 1.0302 & 1.0195 & 1.0240 \\
\hline MI & 1.0686 & 1.0156 & 1.0374 & & 1.0407 & 1.0245 & 1.0312 \\
\hline $\mathrm{MN}$ & 0.9941 & 1.0456 & 1.0238 & & 1.0110 & 1.0250 & 1.0192 \\
\hline MO & 0.9646 & 1.0163 & 0.9944 & & 1.0131 & 1.0222 & 1.0184 \\
\hline MS & 1.0624 & 1.0172 & 1.0358 & & 1.0545 & 1.0255 & 1.0375 \\
\hline MT & 1.0178 & 1.0088 & 1.0125 & & 1.0244 & 1.0084 & 1.0150 \\
\hline $\mathrm{NC}$ & 1.0183 & 1.0315 & 1.0260 & & 1.0469 & 1.0340 & 1.0393 \\
\hline ND & 0.8019 & 0.6046 & 0.7444 & 17 & 1.0373 & 1.0240 & 1.0295 \\
\hline $\mathrm{NE}$ & 1.0326 & 1.0293 & 1.0307 & & 1.0217 & 1.0299 & 1.0265 \\
\hline $\mathrm{NH}$ & 1.0194 & 1.0147 & 1.0163 & 7 & 1.0444 & 1.0132 & 1.0261 \\
\hline NJ & & 1.0344 & 1.0344 & 15 & 1.0156 & 1.0335 & 1.0260 \\
\hline NM & 1.0291 & 1.0477 & 1.0394 & 2 & 1.0344 & 1.0195 & 1.0257 \\
\hline NY & 0.9955 & 1.0269 & 1.0154 & 3 & 1.0160 & 1.0179 & 1.0171 \\
\hline $\mathrm{OH}$ & 0.8738 & 1.0112 & 0.9515 & & 1.0367 & 1.0138 & 1.0233 \\
\hline $\mathrm{OK}$ & 1.0286 & 1.0021 & 1.0131 & & 1.0285 & 1.0063 & 1.0155 \\
\hline OR & 1.2636 & 1.0361 & 1.1070 & 30 & 1.0421 & 1.0117 & 1.0243 \\
\hline $\mathrm{PA}$ & 1.0128 & 1.0316 & 1.0237 & & 1.0214 & 1.0298 & 1.0263 \\
\hline $\mathrm{SC}$ & 1.0267 & 1.0263 & 1.0265 & & 1.0489 & 1.0292 & 1.0374 \\
\hline SD & 1.0119 & 1.1622 & 1.0933 & 2 & 1.0076 & 1.0306 & 1.0209 \\
\hline $\mathrm{TN}$ & 1.0487 & 1.0129 & 1.0277 & & 1.0301 & 1.0127 & 1.0199 \\
\hline $\mathrm{TX}$ & 1.0368 & 1.0133 & 1.0230 & & 1.0302 & 1.0085 & 1.0175 \\
\hline UT & & 1.1738 & 1.1738 & 35 & 1.0111 & 1.0179 & 1.0151 \\
\hline VA & 1.0401 & 1.0320 & 1.0353 & 1 & 1.0295 & 1.0226 & 1.0255 \\
\hline VT & 0.9709 & 1.0229 & 1.0037 & 3 & 1.0465 & 1.0153 & 1.0282 \\
\hline WA & 1.0426 & 1.0398 & 1.0410 & 9 & 1.0437 & 1.0261 & 1.0334 \\
\hline WI & 1.0288 & 1.0106 & 1.0181 & & 1.0071 & 1.0136 & 1.0109 \\
\hline WV & 1.0355 & 1.0293 & 1.0319 & & 1.0218 & 1.0104 & 1.0151 \\
\hline WY & 0.9981 & 1.0668 & 1.0330 & 5 & 1.0147 & 1.0071 & 1.0103 \\
\hline
\end{tabular}


for each state that account for joint production of good and bad outputs. For comparison purposes, we also include the productivity growth rates from Table 1 . First, note that the inclusion of bad outputs in the measurement of productivity growth has a marked impact on the rank order of state growth rates. The Spearman rank correlation coefficient between the two models is 0.32 .

Consider the sub-period 1960-1974. The risk from exposure to pesticides was generally increasing over this period. Therefore, we would expect that a measure of productivity that explicitly accounts for joint production of goods and bads would exhibit slower growth than measures that ignore bad outputs. A comparison of productivity growth rates in Table 3 reveals that for 26 states (AR, AZ, CA, CO, CT, IA, ID, IL, KY, LA, MA, ME, MN, MO, MT, NC, ND, NH, NM, NY, OH, PA, SC, VT, WA, and WY) the MCP index including bad outputs increases more slowly than does the MCP index excluding bads. In eight states (AL, DE, FL, GA, MD, OR, VA, and WV) where the MCP index including bad outputs increases more rapidly, we observe reductions in pesticide runoff. However, in 10 states (IN, KS, MI, MS, NE, OK, SD, TN, TX, and WI), we observe seemingly contradictory results. Our MCP index including bads increases more rapidly, notwithstanding increases in both pesticide leaching and runoff.

Turning our attention to the 1974-1996 period, we see that 36 states achieved reductions in pesticide runoff. However, in 18 of the 36 states, pesticide leaching continued its upward trend. Our MCP index including bads points to slower productivity growth in 10 of these states (GA, IA, IL, IN, MO, MS, NC, NE, OK, and SC). Nineteen states reduced pesticide leaching during this period. Relatively rapid productivity growth was indicated for 13 of the 19 states (AL, CT, FL, ID, MA, MN, NH, NJ, NY PA, SD, TX, and WV). Seventeen states achieved reductions in both pesticide leaching and runoff. Our MCP index including bad outputs grew more rapidly than the alternative measure in 11 of these states (AL, CT, FL, ID, MA, MN, NH, NY, SD, TX, and WV). For two states (KY and LA) where both leaching and runoff increased, slower productivity growth was indicated. Still, for a number of states, we obtain empirical results that appear to be in conflict with our theoretical model. We attribute this to our focus on average growth rates over a period of years rather than on actual year-to-year changes in the series.

To investigate, we examine the time paths of production of the bad outputs and the alternative measures of productivity for selected states. Fig. 4 plot the indexes of pesticide leaching and runoff for Iowa for the period 1960-1996. Observe that pesticide leaching increased sharply from 1960 to 1978, and declined thereafter. The increase in pesticide runoff over this period was less pronounced. If our concern is the measurement of productivity growth over the 1960-1978 period, we would expect the MCP index including bads to increase relatively slowly. Conversely, if our focus is the 1978-1996 period when the production of bads was declining, we would expect this measure to exhibit more rapid productivity growth.

Indeed, Fig. 5 shows a dramatic slowdown in productivity growth between 1960 and 1978 based on the more inclusive measure. The MCP index excluding bads suggests strong productivity growth over this period. The MCP index including bads increased more rapidly over the 1978-1996 period, reflecting the decline in both pesticide leaching and runoff.

In Fig. 6, we present the indicators of environmental risk for Illinois. The risk from pesticide runoff is increasing over the 1960-1979 period and from pesticide leaching over the 1960-1980 period. There are no discernable trends in either leaching or runoff after 


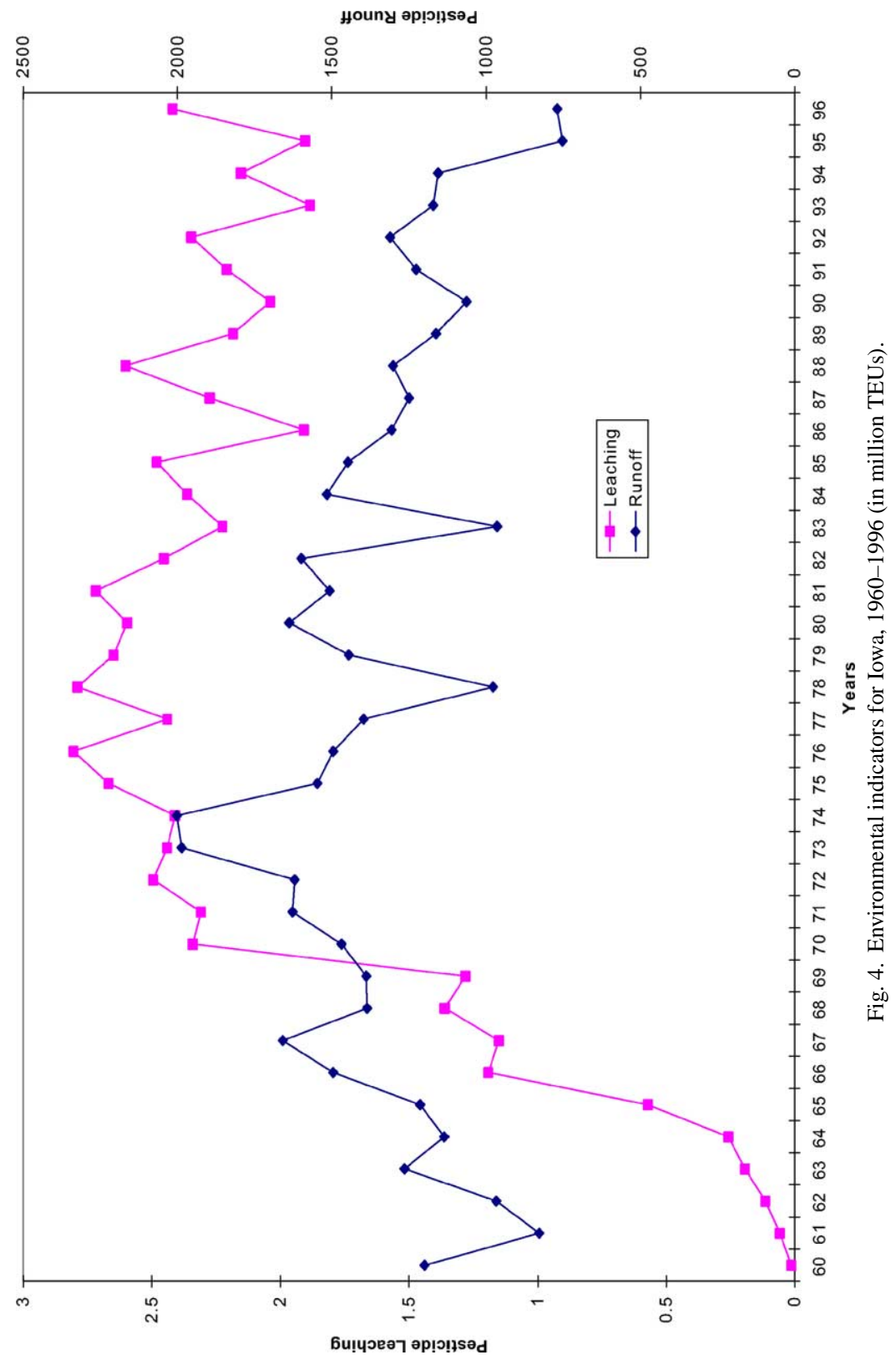




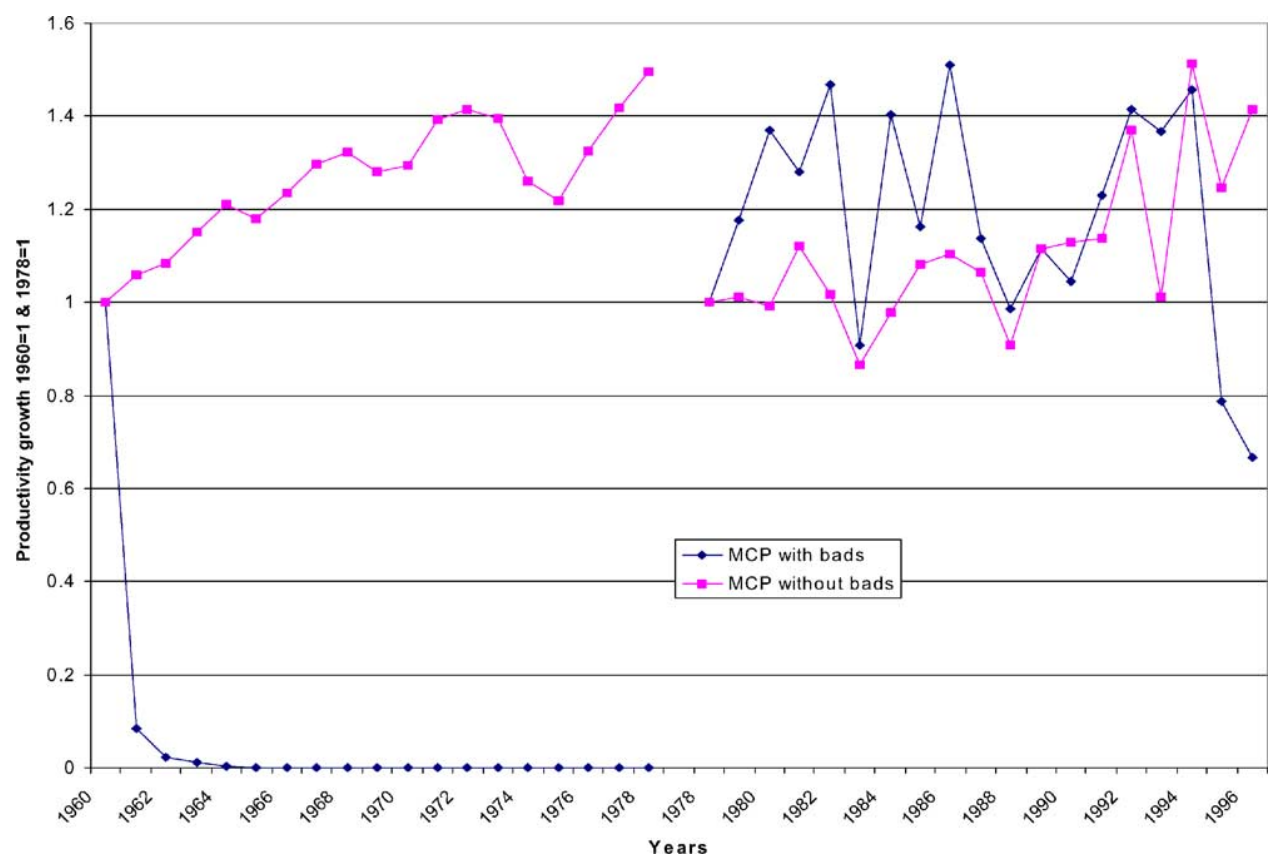

Fig. 5. Alternative productivity growth rates for Iowa, 1960-1996.

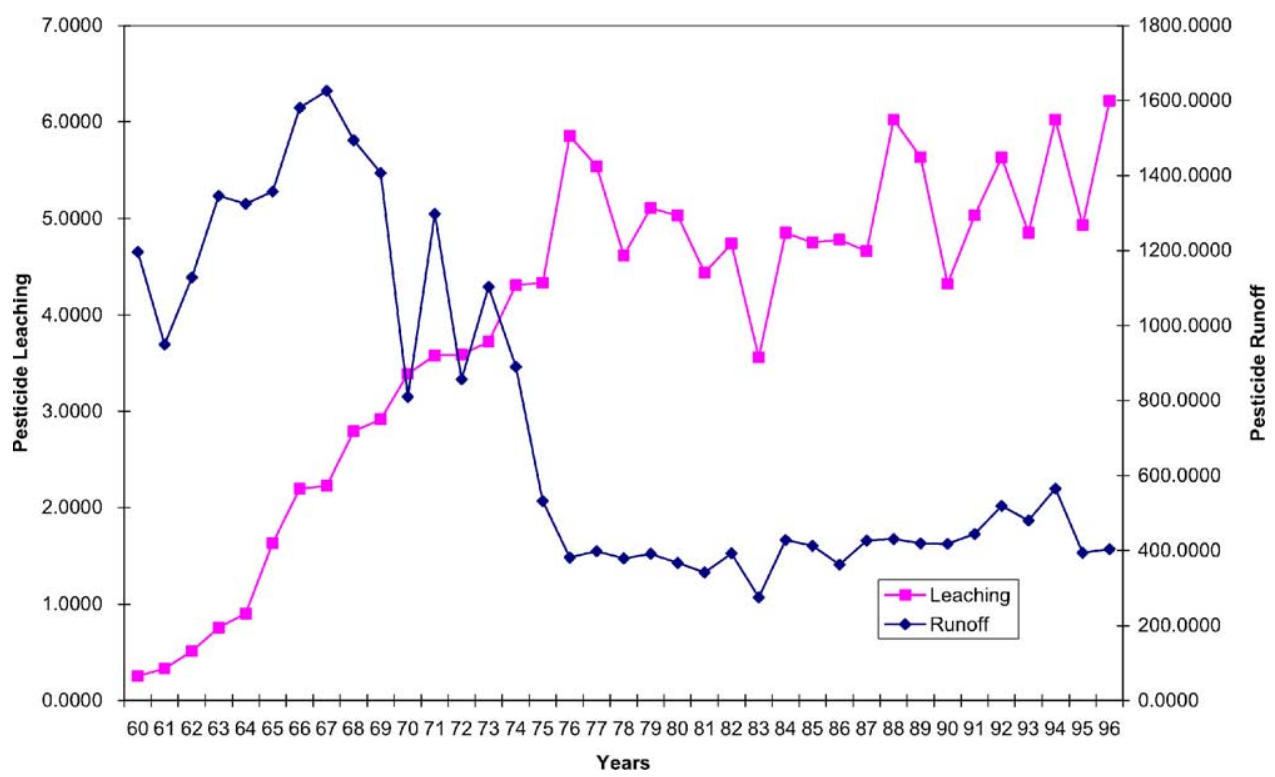

Fig. 6. Environmental indicators for Illinois, 1960-1996 (in million TEUs). 


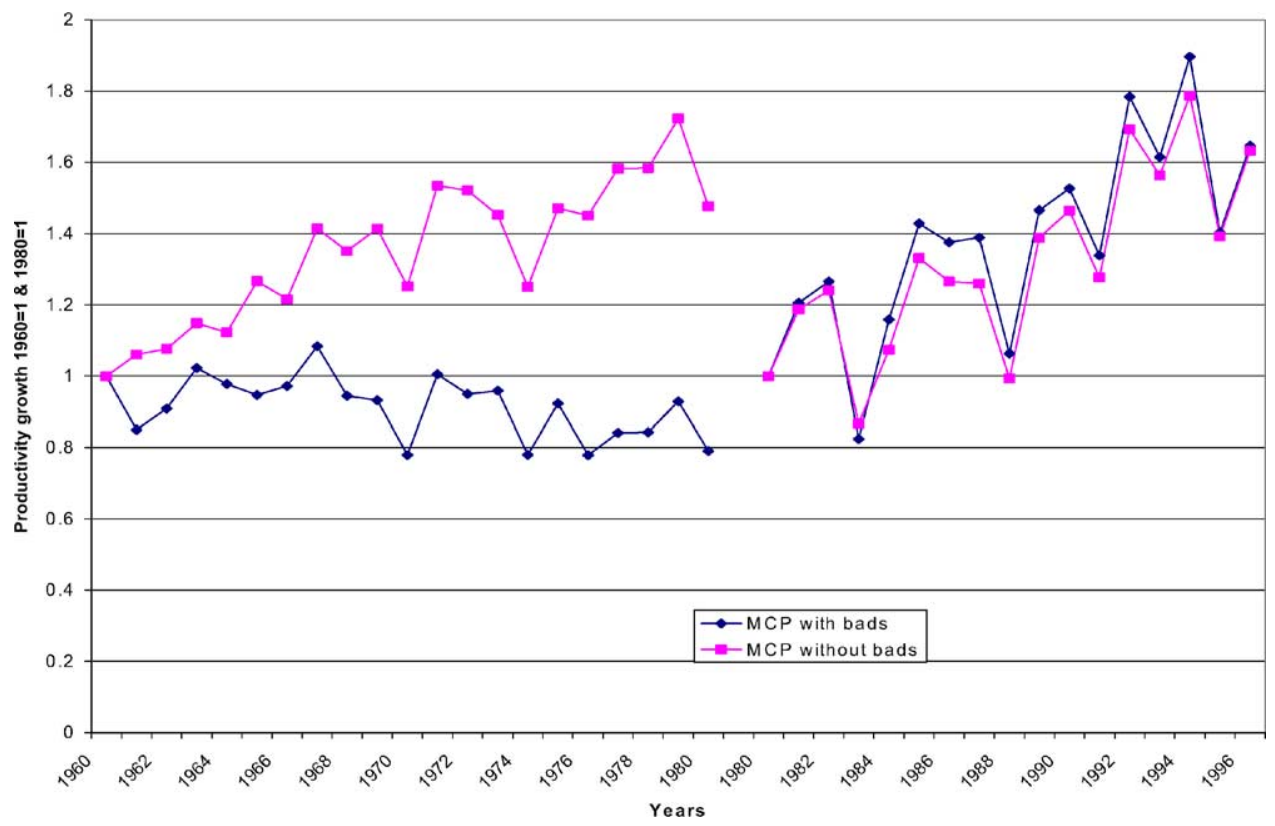

Fig. 7. Alternative productivity growth rates for Illinois, 1960-1996.

1980. Again, when the risks from pesticide leaching and runoff are increasing, we see from Fig. 7 that our MCP index including bads increases more slowly than does the alternative. However, when the level of risk is constant (as is the case for the period 1980-1996), the two measures of productivity growth are quite similar.

Our last state is Nebraska. Fig. 8 plots the time paths of both pesticide leaching and runoff for Nebraska for the 1960-1996 period. We see no discernable trend in pesticide runoff over the entire 37-year period. However, the trend line for pesticide leaching is unmistakably upward sloping. Consider the sub-period from 1968 to 1978 when the risk from pesticide leaching is increasing most rapidly. We see from Fig. 9 that our MCP index including bads increases more slowly. Also note that during the period 1978-1986 when both leaching and runoff trended downward, our MCP index including bads points to more rapid productivity growth. Finally, during the sub-period 1988-1996 when production of both bads are increasing, our MCP index including bads provides a lower bound on our estimates of productivity growth.

We now turn to a discussion of the productivity performance of the aggregate farm sector. ${ }^{6}$ Referring to Fig. 1, we see that both pesticide leaching and runoff increased from 1960 to 1972. Both series trend downward from 1972 to 1984. After 1984, the two series diverge. We plot indexes of productivity growth over these three sub-periods in Fig. 10. And again

\footnotetext{
${ }^{6}$ Productivity growth for the aggregate farm sector is computed as the weighted geometric mean of productivity growth rates across individual states, where the weights are optimal cost shares for each state. These optimal cost shares are computed from the solution of our linear programming problems.
} 


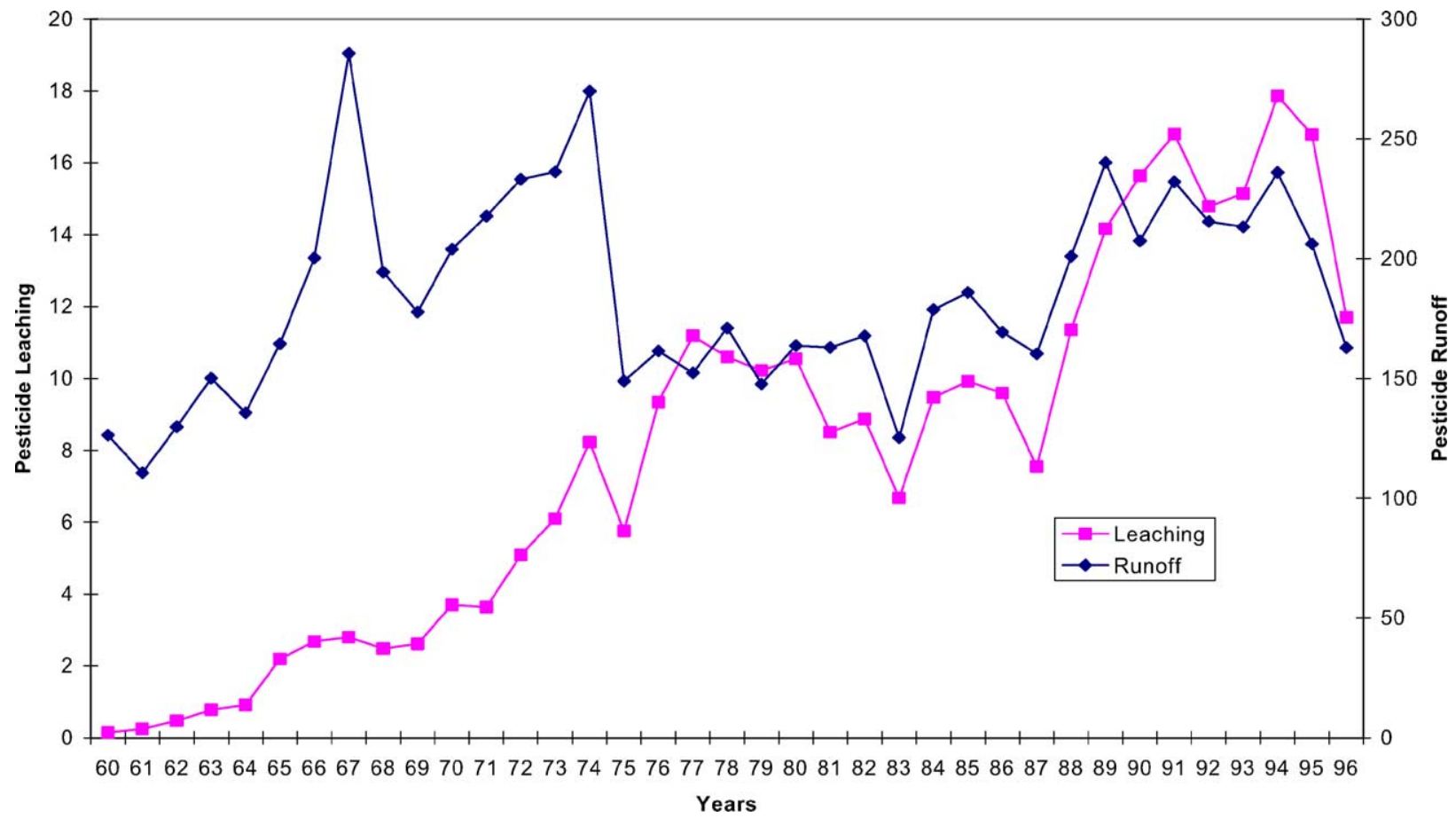

Fig. 8. Environmental indicators for Nebraska, 1960-1996 (in million TEUs). 


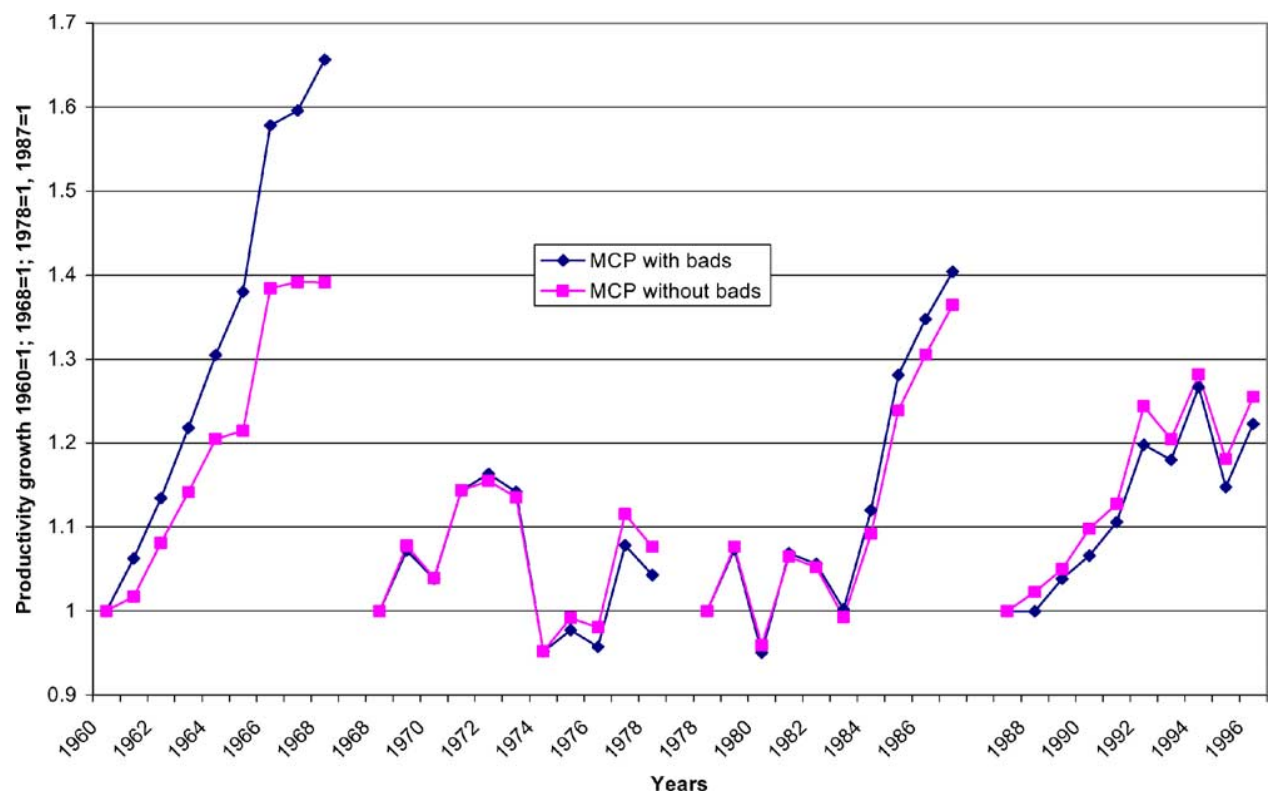

Fig. 9. Alternative productivity growth rates for Nebraska, 1960-1996.

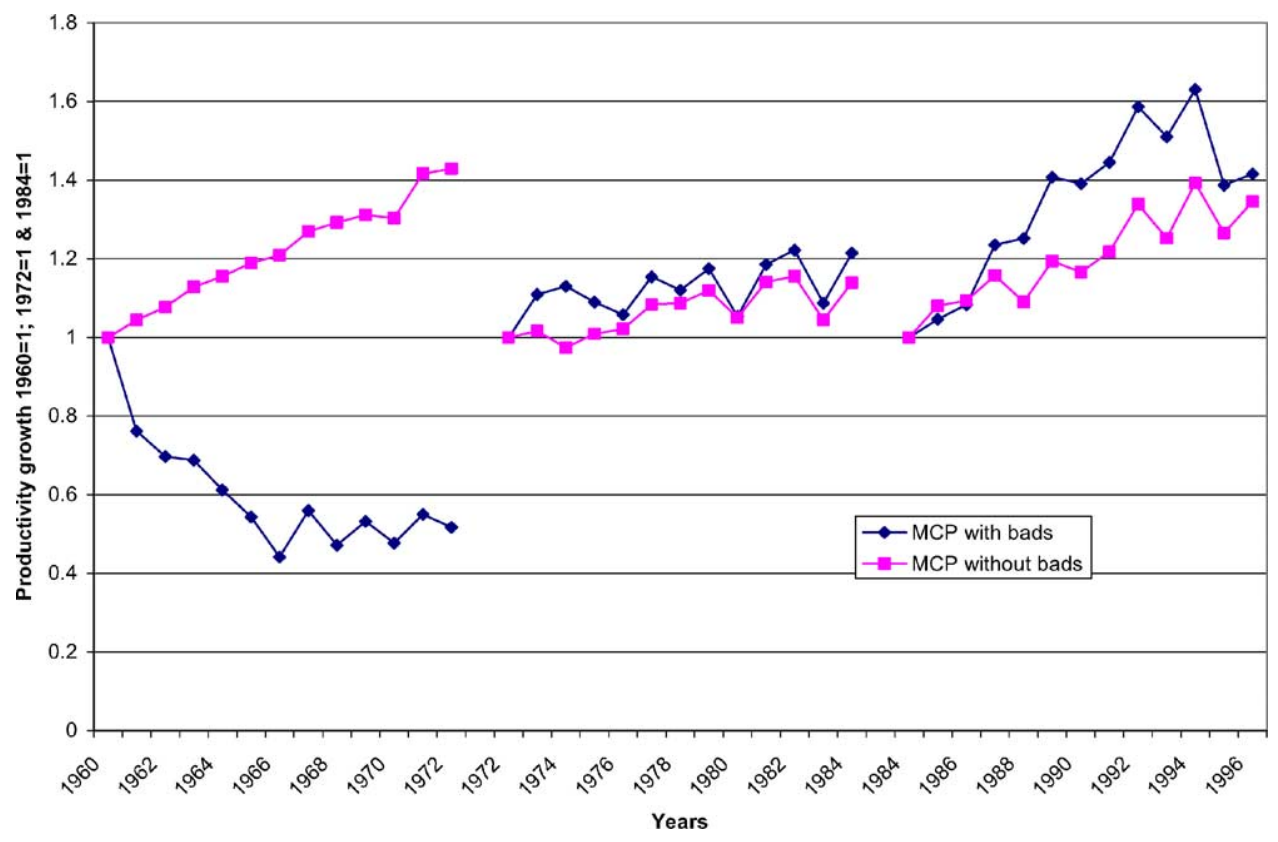

Fig. 10. Alternative productivity growth rates for US Agriculture, 1960-1996. 
we see that ignoring bads when their production is increasing results in an overstatement of productivity growth. In fact, our MCP index including bads shows negative productivity growth over the 1960-1972 period, while its counterpart points to gains in productivity. Ignoring reductions in bads results in an understatement of productivity growth over the period 1982-1984. Finally, when the two series move in opposite directions, as in the 1984-1996 period, our MCP index including bads points to stronger growth in productivity than does the alternative.

\section{Summary and conclusions}

This paper suggests a procedure for measuring productivity growth in the presence of externalities (or other social outputs). The absence of price data for most externalities or social outputs is a limiting factor in measuring productivity growth using conventional growth accounting and index number approaches. Our procedure allows us to model joint production of good output and the external effect without requiring data on (shadow) prices of the externality. This allows us to specify a practical measure of enhanced productivity which can be used as a benchmark for corporate social behavior. Here we focused on environmental responsibility, but the general technique could be adapted to other social outputs.

As an illustration, we provide an application using a state-by-year panel of the US agricultural sector which includes data on environmental risk due to pesticide leaching and runoff. More specifically, we show that measures of productivity growth that ignore bad outputs are biased upward when the production of bads is increasing. Conversely, when the environmental risks associated with production are decreasing, this same measure understates the social benefits of production and, hence, productivity growth.

\section{Acknowledgements}

We are grateful to Robert Kellogg for his helpful comments.

\section{References}

Aigner, D., Chu, S.F., 1968. On estimating the industry production function. American Economic Review 58, $826-839$.

Ball, V.E., Butault, J-P., Nehring, R., 2002a. U.S. agriculture, 1960-1996: a multilateral comparison of total factor productivity. In: Ball, V.E., Norton, G. (Eds.), Agricultural Productivity: Measurement and Sources of Growth. Kluwer Academic Publishers, Boston, pp. 257-276.

Ball, V.E., Färe, R., Grosskopf, S., Nehring, R., 2001. Productivity of the U.S. agricultural sector: the case of undesirable outputs. In: Hulten, C., Dean, E., Harper, M. (Eds.), Studies in Income and Wealth, vol. 63. University of Chicago Press, Chicago, pp. 541-586.

Ball, V.E., Färe, R., Grosskopf, S., Hernandez-Sancho, F., Nehring, R., 2002b. The environmental performance of the U.S. agricultural sector. In: Ball, V.E., Norton, G. (Eds.), Agricultural Productivity: Measurement and Sources of Growth. Kluwer Academic Publishers, Boston.

Ball, V.E., Felthoven, R.G., Nehring, R., Morrison-Paul, C.J., 2002c. Cost of production and environmental risk: resource-factor substitution in U.S. agriculture. In: Ball, V.E., Norton, G. (Eds.), Agricultural Productivity: Measurement and Sources of Growth. Kluwer Academic Publishers, Boston, pp. 293-310. 
Ball, V.E., Lovell, C.A.K., Nehring, R.F., Somwaru, A., 1994. Incorporating undesirable outputs into models of production: an application to US agriculture. Cahiers d' Rconomique et Soiciologie Rurales 31, 59-73.

Chung, Y., Färe, R., Grosskopf, S., 1997. Productivity of undesirable outputs: a directional distance function approach. Journal of Environmental Management 51, 229-240.

Denison, E.F., 1979. Accounting for slower economic growth: the U.S. in the 1970s. Brooking Institution, Washington, DC.

Diewert, W.E., 1992. The measurement of productivity. Bulletin of Economic Research 44, 163-198.

Färe, R., Grosskopf, S., Lovell, C.A.K., 1994. Production Frontiers. Cambridge University Press, Cambridge.

Färe, R., Grosskopf, S., Pasurka, C., 1975. The effect of environmental regulations on the efficiency of electric utilities: 1969 versus 1975. Applied Economics 21, 225-235.

Färe, R., Grosskopf, S., Pasurka, C., 1986. Effects on relative efficiency in electric power generation due to environmental controls. Resources and Energy 8, 167-184.

Färe, R., Grosskopf, S., Tyteca, D., 1996. An activity analysis model of the environmental performance of the firm: application to fossil fuel electric utilities. Ecological Economics 18, 161-175.

Färe, R., Grosskopf, S., Lovell, C.A.K., Pasurka, C., 1989b. Multilateral productivity comparisons when some outputs are undesirable. The Review of Economics and Statistics 71, 90-98.

Farrell, M.J., 1957. The measurement of productive efficiency. Journal of the Royal Statistical Society, Series A 120, 253-290.

Fernandez, C., Koop, G., Steel, M.F.J., 2002. Multiple-output production with undesirable outputs: an application to nitrogen surplus in agriculture. Journal of the American Statistical Association 97, 234-242.

Gray, W.B., 1987. The cost of regulation: OSHA, EPA and the productivity slowdown. American Economic Review 77 (5), 998-1006.

Hailu, A., Veeman, T.S., 2001. Nonparametric productivity analysis with undesirable outputs: an application to Canadian pulp and paper industry. American Journal of Agricultural Economics 83, 605-606.

Havemann, R.H., Christainsen, G.B., 1981. Environmental regulations and productivity growth. Resources for the Future, Washington, DC.

Kellogg, R.L., Nehring, R., Grube, A., Goss, D.W., Plotkin, S., 2002. Environmental indicators of pesticide leaching and runoff from farm fields. In: Ball, V.E., Norton, G. (Eds.), Agricultural Productivity: Measurement and Sources of Growth. Kluwer Academic Publishers, Boston.

Reinhard, S., Lovell, C.A.K., Thijsen, G.J., 1996. Econometric estimation of technical and environmental efficiency: an application to Dutch dairy farms. Paper Presented at the Georgia Productivity Workshop II, Athens, GA.

Reinhard, S., Lovell, C.A.K., Thijsen, G.J., 1997. Environmental efficiency with multiple environmentally detrimental variables; estimated with SFA and DEA. Wageningen Economics Papers, WEP issue, 07-97.

Robinson, J.C., 1995. The impact of environmental and occupational health regulation on productivity growth in U.S. manufacturing. The Yale Journal on Regulation 12, 346-387.

Shephard, R.W., 1970. Theory of Cost and Production Functions. Princeton University Press, Princeton.

Shephard, R.W., Färe, R., 1974. The law of diminishing returns. Zetschrift für Nationalökonomie 34, 69-90.

Simar, L., Wilson, P.W., 2000. Statistical inference in nonparametric fronteir models: the state of the art. Journal of Productivity Analysis 13 (1), 49-78.

Tyteca, D., 1997. Linear programming models for the measurement of environmental performance of firms: concepts and empirical results. Journal of Productivity Analysis 8, 183-198.

Tyteca, D., 1996. On the measurement of environmental performance of firms: a literature review and a productive efficiency perspective. Journal of Environmental Management 46, 281-308.

Zaim, O., Taskin, F., 2000. Environmental efficiency in carbon dioxide emissions in the OECD: a non-parametric approach. Journal of Environmental Management 58, 95-107. 